\title{
KINDERERZIEHUNG IN UNGARN IN DER TRADITONELLEN BÄUERLICHEN KULTUR
}

\author{
Erzsébet GYÖRGYI
}

H-1024 Budapest, Buday László u. 7, Ungarn

Über die traditionelle ungarische Kinderkultur - die bis zur Jahrhundertwende und hie und da auch einige Jahrzehnte länger existierte - wurde bisher keine Monographie verfaßt. Einige gut gelungene Beschreibungen stellen dieses Leben und die Kindererziehung dar. Unter den Autoren sollten in erster Linie Ferenc GÖNCZI (1937) (1949), Mária KRESZ (1942) (1943) (1944) (1948) (1949) (1957) (1959) (1960a) (1960b) und Klára GAZDA (1980) erwähnt werden. Weitere Quellen zur Rekonstruktion des ehemaligen ungarischen Bauernkinderlebens sind die Beschreibungen im Archiv des ungarischen Ethnographischen Museums sowie Archivfotos und Diapositive bzw. die musealen Objekte. In den letzten Jahren ist es Mode geworden, Ausstellungen über Kinderleben und Kinderspiel zu veranstalten. Veranstalter der ersten solchen Ausstellung in Ungarn war ich selbst, im Jahre 1979. (FÖLDESNÉ GYÖRGYI E. 1979, siehe auch 1982a, 1982b, 1987). Dann folgte eine im Veszprémer Museum, von Zsuzsa FODOR-Emőke LACKOVITS (1980), später eine in der Stadt Szentendre, zusammengestellt von Zsuzsa BóDI (1989), und noch einige weitere.

Die ungarischen Bauernkinder wuchsen in der erwähnten Zeit entweder in einer Großfamilie - in welcher drei Generationen zusammenlebten - oder seltener in einer Kleinfamilie auf. Es gab noch wenige klassische Großfamilien in Ungarn, hauptsächlich in den Rückzugsgebieten, wo mehrere erwachsene Brüder mit ihren Familien zusammen unter der Herrschaft des Vaters lebten; diese Art von Familie war aber schon damals im Aussterben.

Das Baby hat so viel Zeit wie möglich mit seiner Mutter zusammen verbracht. Ein neugeborenes Kind wurde in die Wiege gelegt, nachdem es gewickelt und mit einem Band festgebunden worden war. Wenn die Familie mehrere Arten von Wiegen besaß - und das war öfters der Fall -, war die erste Wiege die kleine Wiege. Sie war entweder eine niedrige, verkleinerte Wiege oder ein aus einem Baumstamm geschnitztes trogförmiges Möbelstück. Eigentlich diente sie als ein sehr praktischer Behälter für das zarte Wickelkind in seinen ersten Lebenswochen, wurde aber auch in den späteren Monaten verwendet. Während der Nacht stand sie auf der Bank, die neben das Bett der Mutter gestellt wurde. So konnte die Mutter dem Säugling die Brust reichen und ihn in Schlaf wiegen, ohne aufzustehen. Wenn die Mutter auf das Feld ging, trug sie den Säuling in der kleinen Wiege auf dem Kopf mit. So konnte sie 


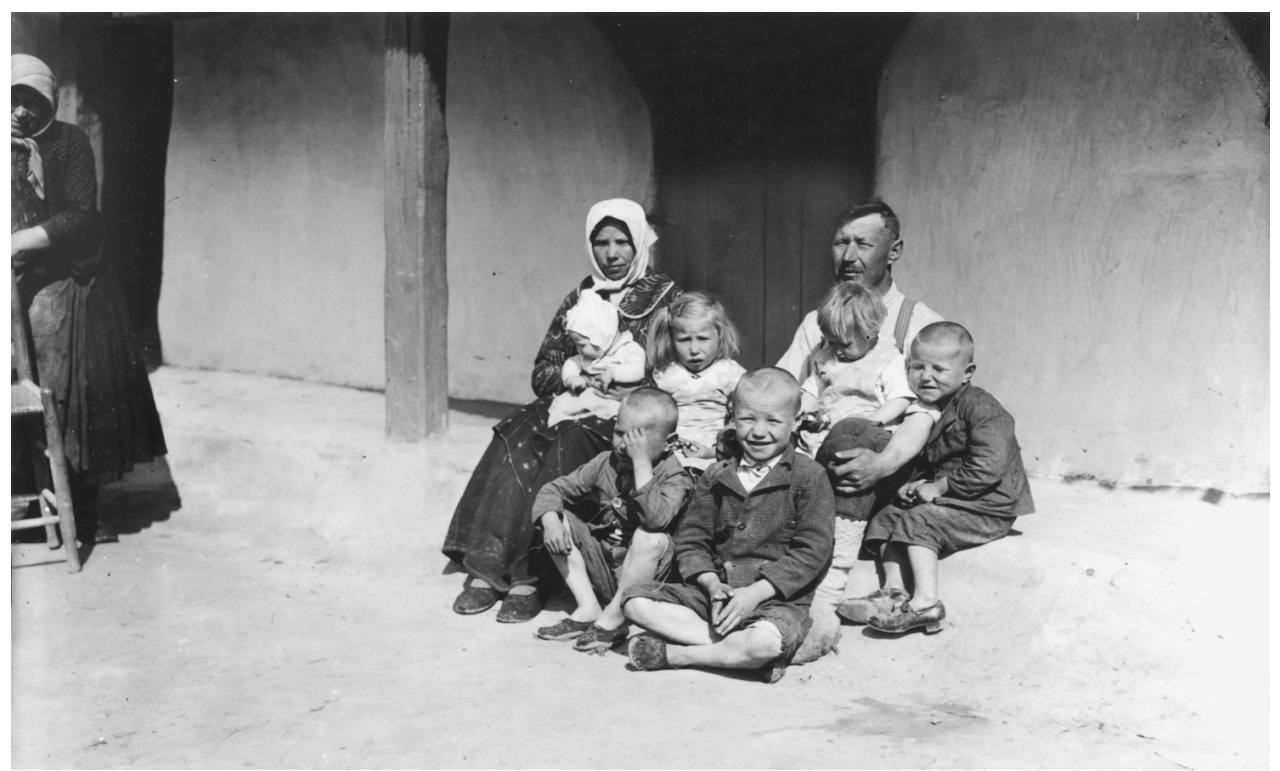

Abb. 1. Bauernfamilie im Dorf Törökkoppány, Südtransdanubien, 1938. Foto: Béla Gunda

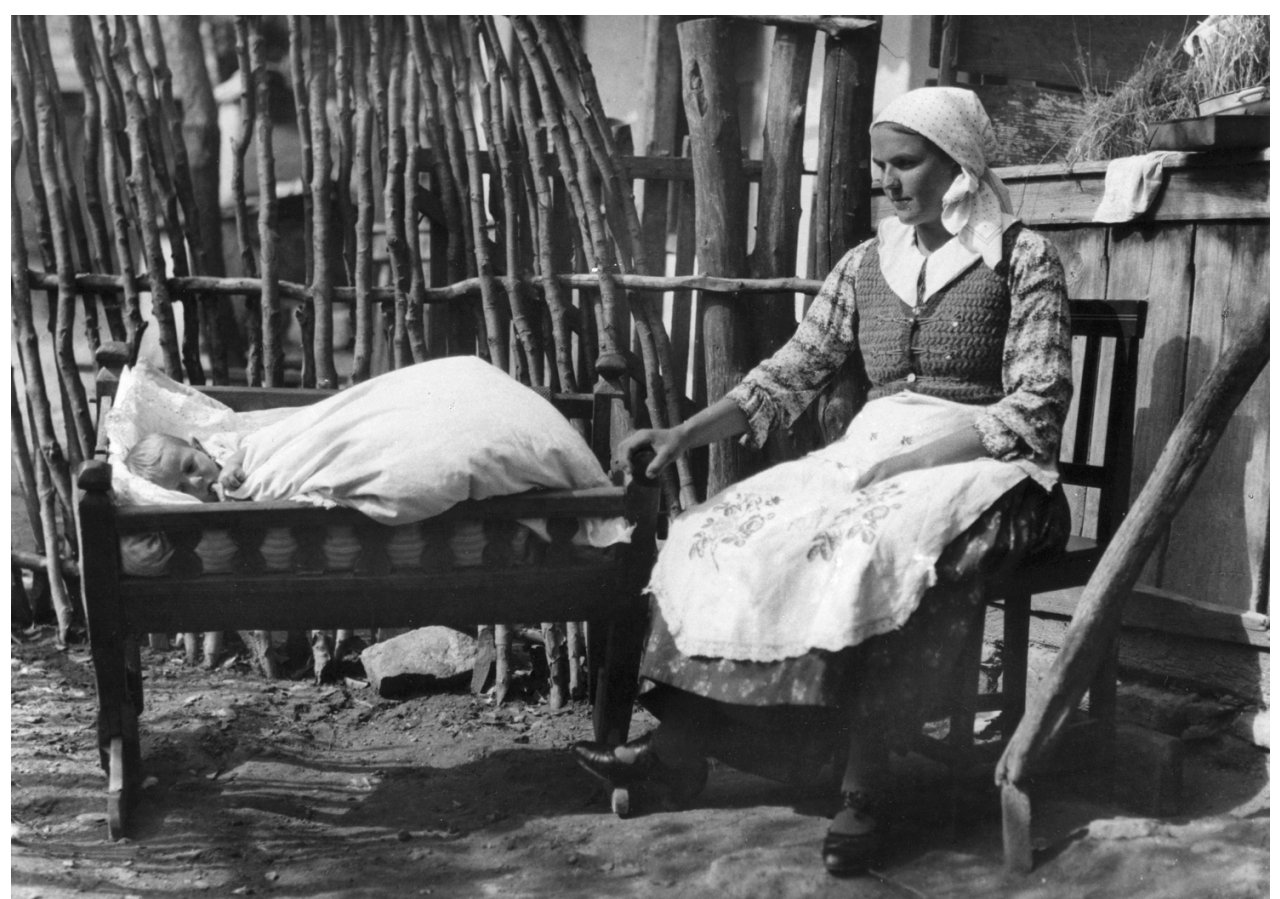

Abb. 2. Junge Mutter mit Wiegenkind im Bauernhof, im Dorf Domaháza, Nordostungarn, 1938. Foto: Oszkár Dincsér 
auch unter freiem Himmel stillen. Auf dem Boden der kleinen Wiege befand sich ein Loch, durch das der Urin abfließen konnte.

Tagsüber lag der Säugling gewöhnlich in der großen Wiege, die in der Stube stand. Diese Wiege war manchmal von Vater selbst verfertigt, öfter aber beim Tischler bestellt oder von ihm gekauft worden. In den Gegenden, wo die Zimmereinrichtung im 19. Jahrhundert in lebendigen Farben bemalt und mit Blumenornamentik verziert wurde, bemalte und verzierte man auch die Wiege. Sie wurde sogar mit dem Monogramm oder den Namen der Eltern versehen. Einige Wiegen wurden so schön verziert, daß man sie als echte Prunkstücke betrachten kann. Die schönsten Wiegen galten als ein Teil der Zimmereinrichtung und wurden selten in andere Räume des Wohnhauses hinübergetragen. Die einfacheren durften auch im Hof aufgestellt werden, wenn die Mutter sich dort betätigte.

Für größere, stärkere Babys genügte ein bunt bezogenes Federkissen, um darin eingewickelt und auf dem Mutterarm getragen zu werden.

Es gab auch eine besondere Wiege, die auf das Feld mitgenommen wurde. Meistens bestand sie aus einem Leintuch oder aus einem vereinfachten Trögchen, welches an einer aus Balken zusammengestellten Konstruktion (drei oben zusammengebundene Balken oder zweimal zwei Balken mit einem Querbalken) aufgehängt wurde. In dieser sogenannten „Wiesenwiege“ konnte das Kind ruhig einschlafen. Gegen Fliegen konnte die Wiege mit einem Leintuch zugedeckt werden.

Es wurde aber nicht immer und überall eine solche Wiege verwendet. (Wie schon erwähnt, konnte dazu einfach die kleine Wiege dienen.) Viele Babys blieben zu Hause, während die Mutter auf dem Feld arbeitete. Die Babys wurden von größeren Geschwistern, Schwägerinnen der Mutter, Nachbarinnen oder von der Großmutter versorgt - manchmal gut, manchmal aber wurden sie auch vernachlässigt.

Vielleicht sind ungarische Bauernkinder schon in der Stehschule Beobachter geworden. Die Stehschule wurde aus Holz gefertigt, oft von einem geschickten Bauern, seltener von einem Tischler. In der Platte der Stehschule befindet sich nicht selten eine kleine Vertiefung, in ihrer Form einem Schüsselchen ähnlich. Dem Kind wurde hierin etwas zu essen gegeben. Manche Stehschulen sind mit Rädern versehen worden und erlaubten ein wenig Bewegung. In der Stehschule war das heranwachsende Kind vielleicht isoliert und einsam, vor allem dann, wenn diese unbeweglich war. Einen gewissen Vorteil hatte die Stehschule aber gegenüber der Wiege: von ihr aus konnte man vieles sehen, sogar beobachten. In unserem Archiv gibt es viele Fotos von Kindern, die einfach in die weite Welt hineinschauen.

Für ungarische Bauernkinder gab es bis in die Mitte unseres Jahrhunderts keine „Kinderzimmerkultur“. Die Wohnungen waren im Verhältnis zur Zahl der Familienmitglieder eng, oft schlief die ganze Familie, Eltern und Kinder, in demselben Raum. Es wurden zwar Wohnungsteile bestimmt, wo Kinder sich aufhalten durften, aber ganz abgesondert von den Erwachsenen waren sie zu Hause nie. Es bedeutete oft ein Problem, einen freien, ruhigen Platz zu finden, wo sich das Kind ungestört mit seinen Schulaufgaben beschäftigen konnte.

Die Kinder waren aus dem Leben der Erwachsenen nicht ausgeschlossen. Es fällt auf unseren Fotos auf, daß Kinder bei verschiedensten Ereignissen des Alltagslebens 


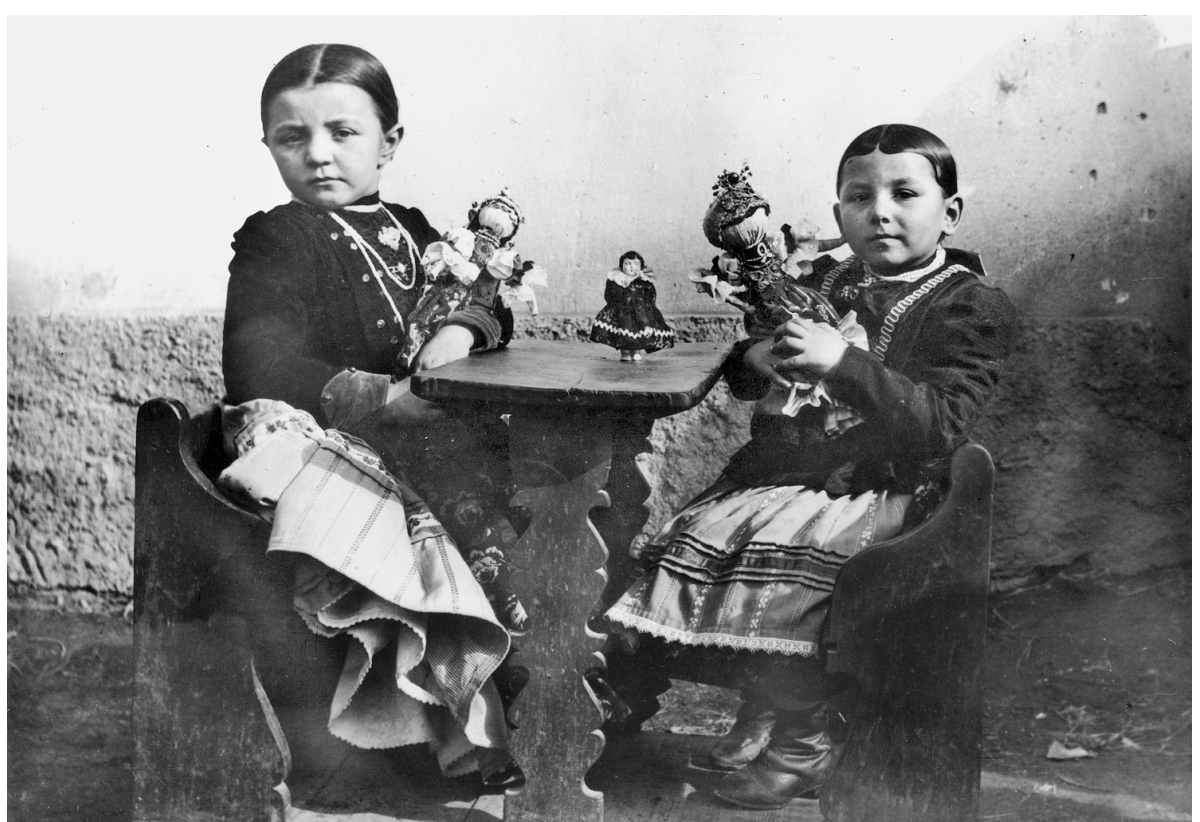

Abb. 3. Schulmädchen mit ihren zu Hause verfertigten Puppen. Dorf Egyházasmarót, Nordungarn, 1914. Foto: Samu Borbál

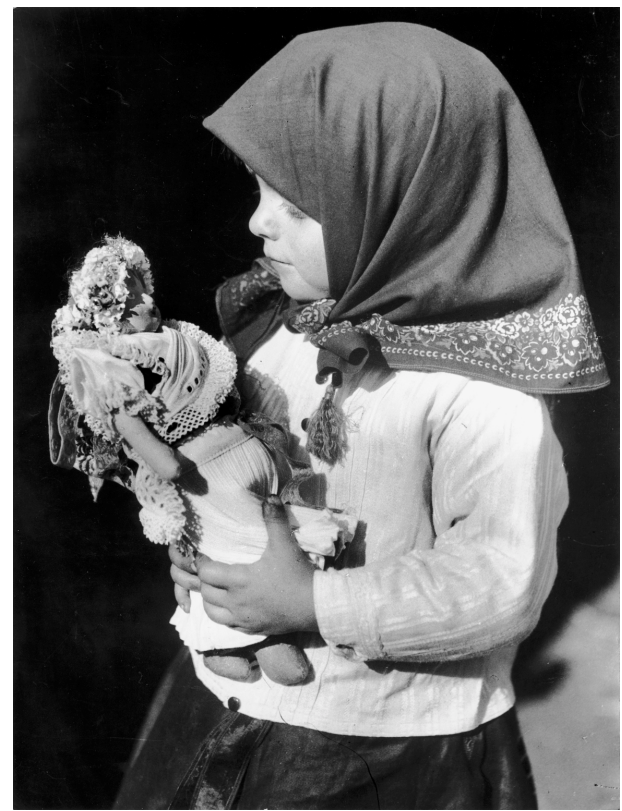

Abb. 4. Mädchen mit als Braut angekleideter Puppe im Dorf Boldog, Kom. Pest, 1936. Foto: Sándor Gönyey 


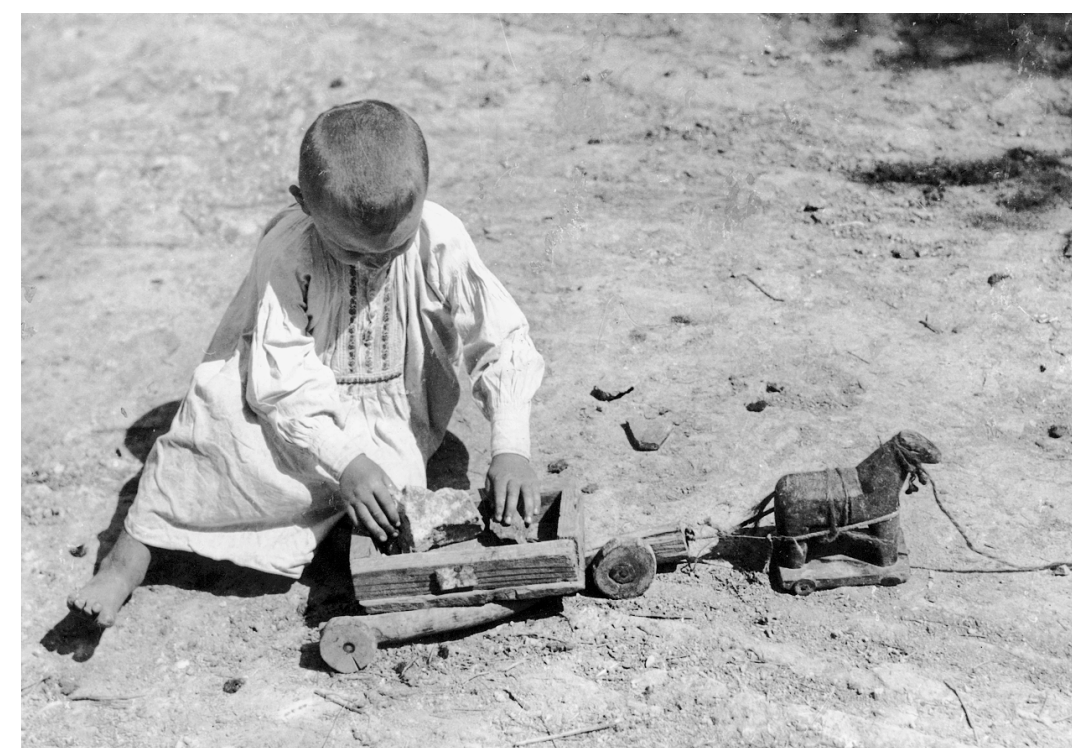

Abb. 5. Knabe mit der gebastelten Kutsche spielend im Dorf Hollókó, Nordungarn, 1930. Foto: Gertrud Palotay

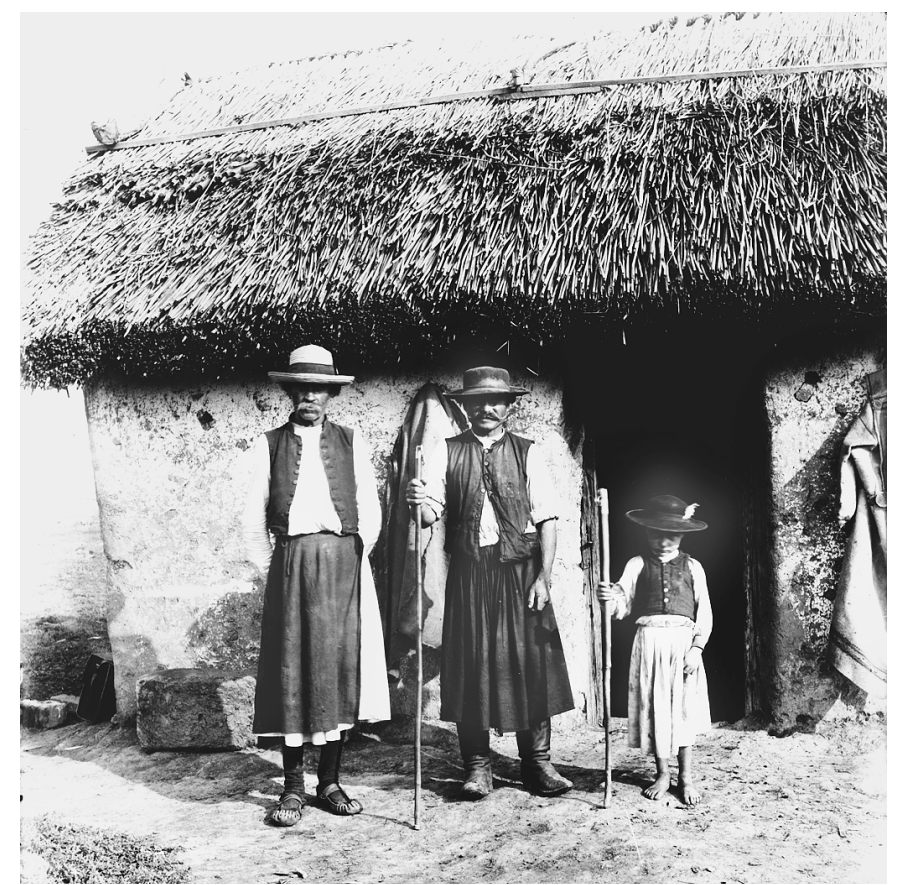

Abb. 6. Hirtenknabe mit den erwachsenen Schafhirten, Ohat puszta, Komitat Hajdu, 1907. Foto: István Györffy 
und bei festlichen Gelegenheiten immer dabei waren. Man kann behaupten, daß sie stets bereit waren, alles Interessante, Gewöhnliches oder Ungewöhnliches, wahrzunehmen und zu beobachten.

Die Arbeitstätigkeit der Eltern und anderer Erwachsener war oft das Objekt der Beobachtung, wozu es im Alltagsleben häufig Möglichkeiten gab. Wenn die erwachsenen in Gemeinschaft arbeiteten, fehlten auch die Kinder nicht, die größeren arbeiteten mit, die kleineren störten vielleicht, aber alle haben das Erlebnis mit sich genommen, wie eine gewöhnliche Arbeit, etwa das Maisschälen, vor sich ging. Sie konnten auch dann zuschauen, wenn ein Töpfer, Glaser oder ein Wanderhändler ins Dorf kam, und durch die Siedlung ging, um seine Waren zu verkaufen oder in den Haushalten etwas zu verbessern.

An den gemeinsamen „Kulturerlebnissen“ der Dorfleute hatten sogar die kleinsten Kinder ihren Anteil. So etwa, wenn ein Wandermusikant eine entlegene Siedlung aufsuchte oder wenn der alte Märchenerzähler seinen erwachsenen Zuhörern eine Geschichte vortrug. Bei der Taufe, einem Hochzeitsfest in der Verwandtschaft oder bei der Bestattung eines Familienmitgliedes hatten die Kinder auch das Recht, festlich angezogen dabei zu sein. Bei der Hochzeit durften sie selbst miteinander tanzen und mußten nicht nur den Erwachsenen zuschauen. Das Beobachten des künftigen Lebens - in Gestalt des Lebens der Eltern und anderen Erwachsenen war von großer Bedeutung für den Sozialisationsprozeß der Kinder, zumindest insofern, als die meisten Situationen, die im ländlichen Leben vorkamen, einem Heranwachsenden nie vollkommen unbekannt blieben. Dadurch haben die Kinder sich gewiß spätere Überraschungen erspart. Das Lieblingsspiel der Kinder war, eine Hochzeit zu veranstalten, das wirkliche Leben zu spielen.

Noch mehr hat zur Sozialisation der Kinder das Spielen und die regelmäßige Teilnahme an der Arbeit, das Eingegliedertsein in die familiäre Arbeitsteilung beigetragen. Manche Spiele halfen mit, verschiedene Fähigkeiten zu entwickeln - die Bewegungsspiele mit Tanzen, Springen, Hüpfen, Laufen usw. -, vor allem aber bereiteten sie den Kindern viel Freude. Auch unter den Spielgeräten gab es solche, die ebenfalls diesem Zweck dienten: durch das Spielen mit ihnen wurden Geschick, Schnelligkeit, Augenmaß, Gehör und ähnliches geübt und entwickelt. Viele Spielgeräte haben das Kind dagegen besonders auf die Arbeitstätigkeit der Erwachsenen vorbeitet. Es wurden kleine Arbeitsgeräte als Spielzeug hergestellt, von den Eltern wie von den Kindern. Die Kinder spielten gerne die Tätigkeiten nach, die die Erwachsenen zu verrichten pflegten. Unter den geliebten Spielgeräten der Kinder gab es kleine Wagen und Kutschen, ins Joch eingespannte Ochsenpaare oder Pferde, Arbeitsgeräte aus dem Ackerbau und verschiedenen Gewerben, Musikinstrumente, Waffen, Küchengeräte, Möbel, Häuser und Hauserinrichtungen. Manche Eltern haben ihre Kinder mit Bedacht in den Jahren, in denen sie die wirkliche, effektive Arbeit zu erlernen begannen, mit verkleinerten Arbeitsgeräten beschenkt. Dadurch wurde die Einführung in die Arbeit erleichtert. Die frühe Bekanntschaft mit der Arbeitswelt hat eine späte Umstellung auf die Arbeit erspart. Die Arbeit wurde zum Spiel und dadurch zum Vergnügen gemacht.

Aber es konnte auch anders sein. Die ersten Schritte des Kindes in der Welt der 


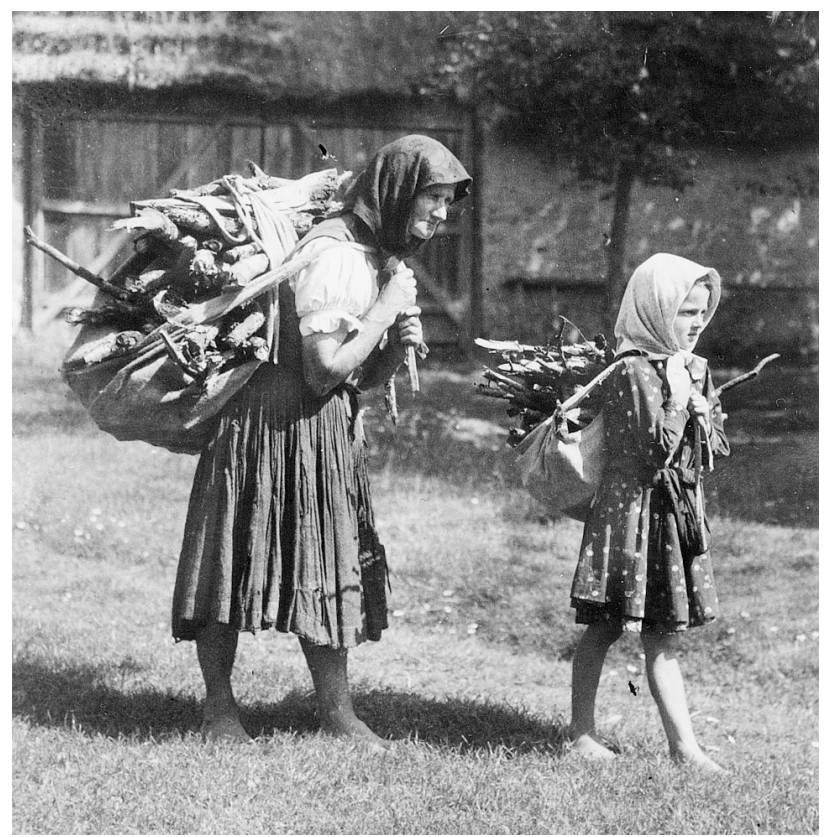

Abb. 7. Großmutter und Enkelkind schleppen das Holz nach Hause im Dorf Pusztafalu, Nordungarn, 1939. Foto: Sándor Gönyey

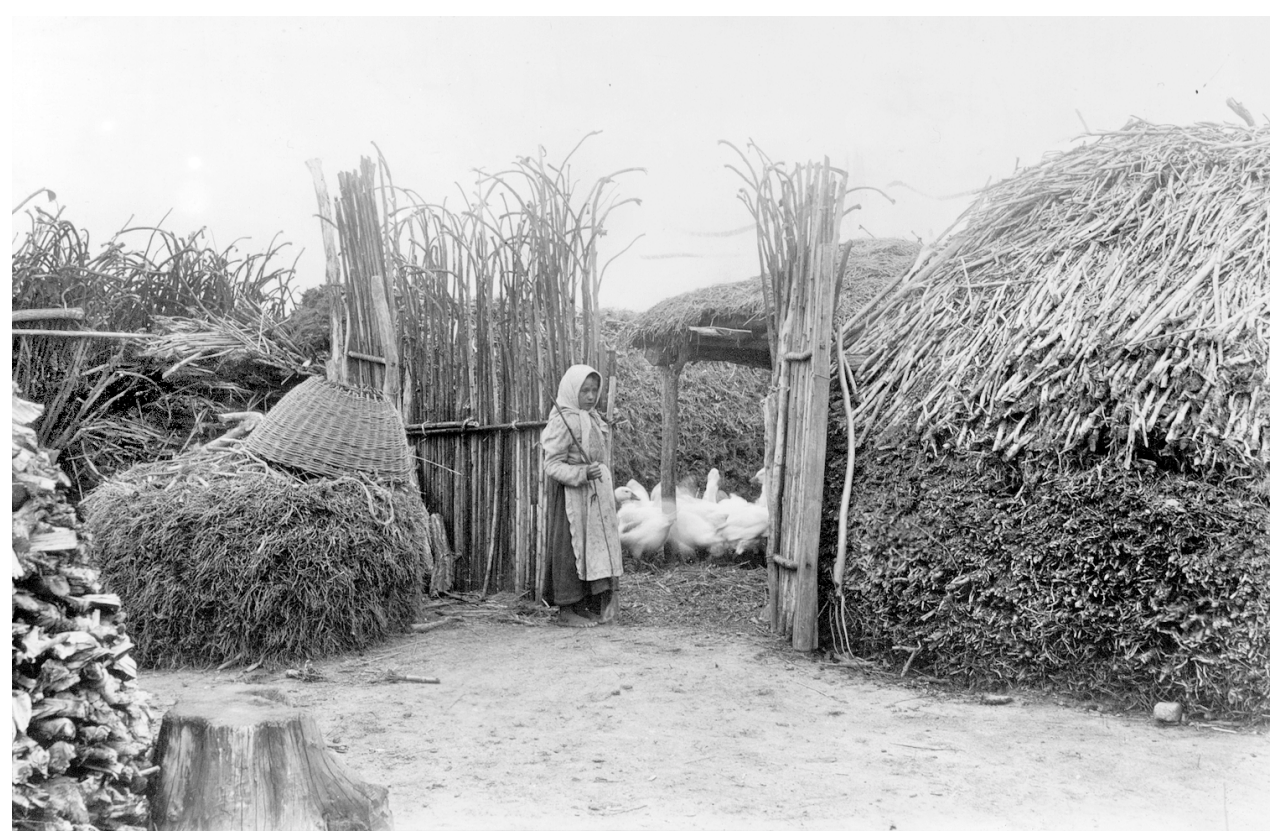

Abb. 8. Kleine Gänsehirtin im Dorf Jászapáti, Große Ungarische Tiefebene, 1903. 


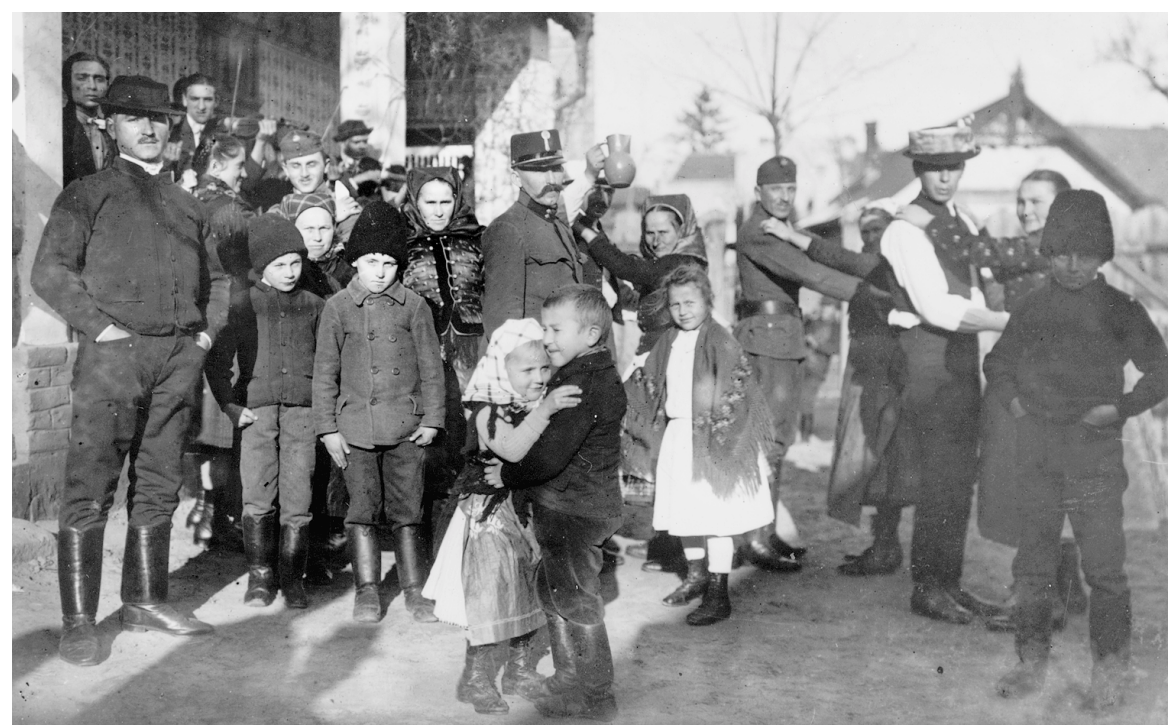

Abb. 9. Hochzeitstanz, die Kleinen tanzen auch mit. Dorf Fót bei Budapest, 1923. Foto: Sándor Gönyey

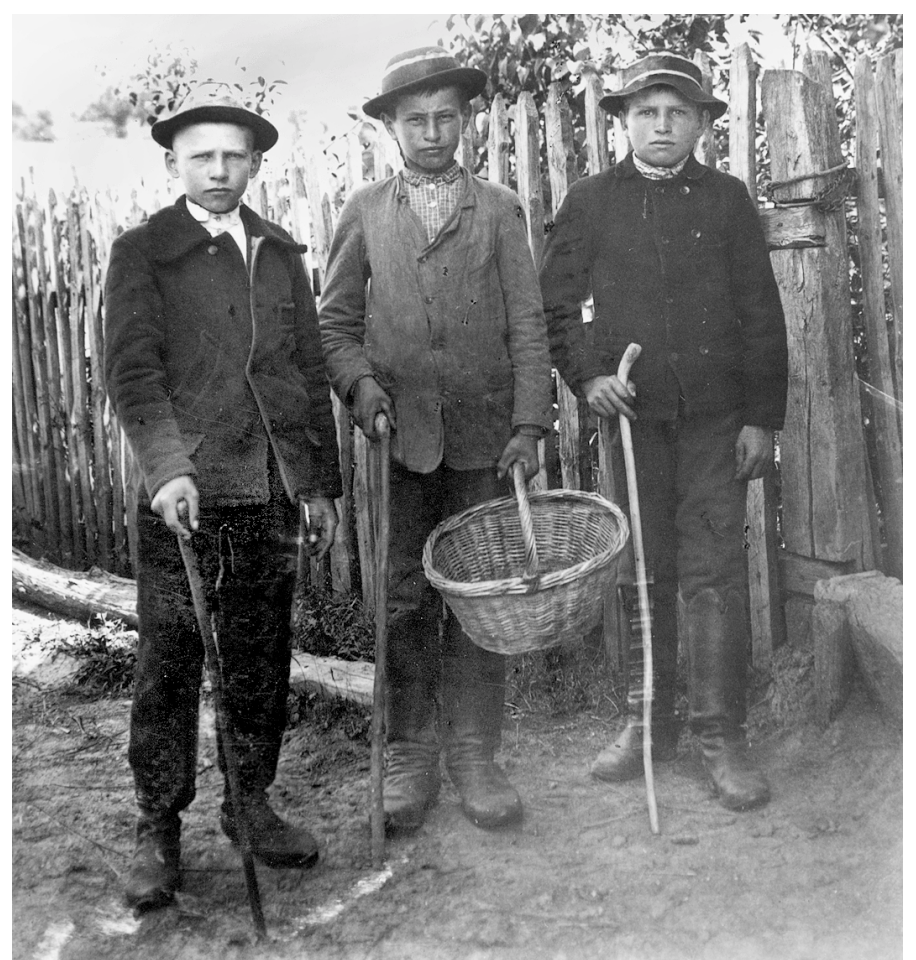

Abb. 10. Gabensammelnde Knaben am Gregoriustag im Dorf Kustánszeg, 1904. Foto: Zsigmond Bátky 
Arbeit waren weitgehend von den materiellen Verhältnissen der Eltern abhängig. In einer wohlhabenden Familie hat das Kind nur Aufgaben bekommen, die seinen Kräften angemessen waren: das Mittagessen für den Vater auf das Feld hinauszutragen, Steine vom Feld zu sammeln, mit der Mutter gemeinsam grüne Bohnen zu pflücken oder von ihr spinnen zu lernen, mit der Großmutter Holz auf dem Rücken zu tragen, das alles waren nicht zu schwere Aufgaben. Den Viehbestand der Familie hüten war oft schwieriger, aber es war doch der eigene Vater, dem das Kind verantwortlich war. Die Lohnarbeit, die viele Kinder mit 6 bis 8 Jahren übernehmen nußten, war meistens ebenfalls das Viehhüten. Die Verantwortung gegenüber dem fremden Bauern und die machmal große Zahl der Kühe, Schweine oder Gänse haben diese Tätigkeit sehr erschwert. Viele Eltern waren gezwungen, ihre minderjährigen Kinder für Kleidung und Essen bei reichen Bauern in Dienst zu geben. Mädchen dienten als Gänsehirtinnen, kleine Mägde oder Kindermädchen. Sie waren den Launen der Bäuerinnen ausgesetzt. Die Tochter eines wohlhabenden Bauern dagegen bekam einen kleinen Webstuhl, später einen größeren, und erlernte allmählich, Schritt für Schritt, die Kunst des Webens. Die Mädchen auf der Wiese haben beim Gänsehüten zusammen gespielt und voneinander gelernt, Puppen zu verfertigen und Puppenkleider zu nähen.

Die Teilnahme an den Volksbräuchen gehörte zu den schönsten Seiten des Kinder- und Jugendlebens. Bei den Rollenspielen in diesen Volksbräuchen haben die Kinder und Jugendlichen verschiedene Verhaltensweisen erlernt. Für ihre Präsentation bekamen sie von den Dorfbewohnern Geschenke und wurden von ihnen anerkannt. Die Anlässe dafür gaben die Feiertage des Kirchenjahres: das Krippenspiel und das Neujahrssingen in der Weihnachtszeit, danach die Faschingsbräuche, das Todaustragen, die Frühlingsbräuche um Ostern oder das Spiel mit der Pfingstkönigin stellten die Kinder vor viele Aufgaben. Man mußte das sittliche Benehmen, Begrüßen und Verabschieden, die Texte und die Gesten, die Bewegungen, die gesamte Choreographie genau kennen und wissen, sonst blieb der Erfolg aus. Das Sammeln nach dem Spiel erfolgte in manchen Fällen nicht für sich selbst, sondern für andere Zwecke, zum Beispiel am Gregoriustag für die Schulen.

Das Kinderleben im ehemaligen ungarischen Dorf war nicht leicht. Aber das Baby war Tag und Nacht mit der Mutter zusammen. Das Kind konnte, durfte und mußte alles sehen und fing schon im Kindesalter an, sich mit seinen späteren Tätigkeiten, der Arbeit, zu beschäftigen; sein Spiel enthielt Elemente der Arbeit. Volksbräuche halfen beim Prozeß der Sozialisation, sie hatten in dieser Hinsicht vielleicht eine wichtigere Rolle als die Volksschule, die von den Bauernkindern so oft vernachlässigt wurde. Vieles von dem, was das Kind umgab, war von Personen angefertigt worden, die ihm nahe standen. 


\section{LITERATUR}

BóDI, Zsuzsa

1989: Gyermekélet a századelőn (Kinderleben am Jahrhundertbeginn). Népmúvészetek Háza, Szentendre.

FODOR, Zsuzsa-LACKOVITS, Emóke

1980: A falusi gyermekek élete Veszprém megyében 1868-1945. Das Leben der Kinder vom Lande im Komitat Veszprém, in den Jahren 1868-1945. Veszprém.

FÖLDESNÉ GYÖRGYI, Erzsébet

1979: Gyermekélet a régi magyar faluban (Kinderleben im alten ungarischen Dorf). Budapest.

1982a: Tradition in Hungarian Education of Peasant Children. Budapest-Kecskemét.

1982b: Kinderleben im ehemaligen ungarischen Dorf. Eine Ausstellung im Ethnographischen Museum Budapest. Hessische Blätter für Volks- und Kulturforschung 13, 209-214.

1985: Traditionelle Kinderkultur im ländlichen Ungarn. Kinderfotos als Ausstellungsmaterial. In: Kinderkultur. 25. Deutscher Volkskundekongress in Bremen vom 7. bis 12. Oktober 1985. Bremen, 1987. 85-94.

GAZDA, Klára

1980: Gyermekvilág Esztelneken (Kinderwelt in Esztelnek). Bukarest.

GÖNCZI, Ferenc

1937: Somogyi gyermek (Das Kind in Somogy). Kaposvár.

1949: Somogyi gyermekjátékok (Kinderspiele in Somogy). Kaposvár.

KRESZ, Mária

1942: Gyermekélet és játék Sárpilisen (Kinderleben und Spiel in Sárpilis). In: Tanulmányok egy sárközi falu társadalmáról. Budapest, 45-62.

1943: A pólyázás Nyárszón (Das Babywickeln in Nyárszó). Néprajzi Értesítő, 173-175.

1944: A gyermekkor és ifjukor néprajza egy kalotaszegi faluban. (Die Volkskunde der Kinder- und Jugendzeit in einem Dorf im Kalotaszeg). Ethnologisches Archiv (EA) im Ethnographischen Museum in Budapest, Inv. Nr. 4435.

1944: A gyermekkor és az ifjukor néprajza egy kalotaszegi faluban (Die Volkskunde der Kinder- und Jugendzeit in einem Dorf im Kalotaszeg). Ethnographia LV. 143-147.

1948: A magyar népi gyermekjátékok kutatása (Die Erforschung der ungarischen Kinderspiele). Klny. a Magyar Népkutatás Kézikönyvéból, Budapest.

1949: A hagyományokba való belenevelődés egy parasztfaluban (Das Hineinwachsen in die Traditionen in einem Bauerndorf). In: ORTUTAY, Gyula (Hrsg.) Néprajzi Tanulmányok. Budapest, 5394, 140-145.

1957: A gyermekek és fiatalok viselete a kalotaszegi Nyárszón (Die Tracht der Kinder und Jugendlichen in Nyárszó im Kalotaszeg). Néprajzi Értesítő, 103-121.

1959: Játék a kalotaszegi Nyárszón (Spiel in Nyárszó im Kalotaszeg). Néprajzi Közlemények, 172203.

1960a: A fiatalság társas élete a kalotaszegi Nyárszón (Das gesellige Leben der Jugend in Nyárszó im Kalotaszeg). Néprajzi Közlemények, 93-121.

1960b: A kisbuba és anyja Nyárszón (Das Kind und seine Mutter in Nyárszó). Néprajzi Közlemények, 220-258. 